\title{
A STUDY ON THE ROLE OF TEACHERS IN MITIGATING GENDER ISSUES IN CLASSROOM TRANSACTION
}

\author{
Anu J. Vengal \\ Assistant Professor, Titus II Teachers College, Thiruvalla \\ annuvengal@gmail.com
}

\begin{abstract}
The aim of this study on the Role of Teachers in Mitigating Gender Issues in Classroom Transactions was to explore the key aspects related to the teacher's role in alleviating gender issues and biases and the means through which teacher tends to minimize the gender discriminations and issues. The literature review done to collect data showed that Administrative Management Theory and Behavioral Management Theory can play a major role in bringing a positive change in the classroom environment. The study relies on extensive analysis and interpretation of secondary qualitative data through surveys of related studies. The researcher could come up with some themes that can play extensively in diminishing gender divides in learning environments. Even though primary data is not analyzed, which can be seen as a limitation of the study, the present probe into the areas of gender equality in the classroom and the importance of starting it from the schools focus lights on to new avenues of gender sensitization in the education system.
\end{abstract}

Keywords: Teacher's role, gender issues, classroom transaction, mitigating.

\section{INTRODUCTION}

\subsection{Introduction}

Boys don't cry! Girls don't fly! Women are natural nurturers; men are natural leaders! We often get astonished about the origin of gender roles. Who made these gender roles? We understand that it exists, even though our system is making deliberate actions to curb gender bias and promote equity. All institutions of society exhibit this gender disparity as gender is rarely thought to be important and hardly understood and addressed (Allana et al., 2010). Teachers and educators influence the gender roles of their students, impacting their educational outcomes. When considering education for all, It should be realised that teachers are a critical force for meeting the goal (UNESCO, 2005) Educators greatly influence gender roles of students, this having an impact on quality of life and power distribution.

Considering the literature review research context, that seeks a comprehensive study pertaining to the key role that a teacher plays in mitigating gender issues within the periphery of classroom transaction, it is essential to address the research accurately so that a positive research outcome can be acquired. It is unprecedented and noteworthy that the significance of 
nurturing gender sensitivity within a classroom is deemed as a highly important aspect, for which a teacher is solely responsible. The very phenomenon of classroom transaction reflects empowering children for participating in classroom activities through the framing of problems and asking questions.

\subsection{Research Aim}

The aim of this significant literary research context focuses on comprehending the effective role of teachers in mitigating gender issues within classroom transactions.

\subsection{Research Objectives}

The objectives of the research assessment involve,

- To identify the teacher's role in mitigating gender issues in classroom transactions.

- To understand the ways to minimize gender issues in classroom transactions.

- To identify the factors that influence gender issue mitigation in classroom transactions.

\subsection{Research Rationale}

The present research mainly denotes the effective roles of the teacher in minimizing the instances associated with gender issues, within the classroom transaction. Gender biases and prejudices are negative elements that obstruct the potentiality of the classroom and even develop obstacles in the path of universal learning that starts with gender equality. Thus, the emphasis of the study is to probe the thought and mentality of gender biases that give way to gender issues within the perimeter of classroom transactions.

\subsection{Research Questions}

The research questions are.

1. What is the role of a teacher in mitigating gender issues in classroom transactions?

2. What are the ways of mitigating gender issues in classroom transactions?

3. What are the factors that influence gender issue mitigation in classroom transactions?

\section{LITERATURE REVIEW}

\subsection{Introduction}

According to the literature review research context, the teachers hold an area of great importance in mitigating gender biases and gender issues associated with classroom transactions. To understand the area of research and the essence of the study in an effective manner, it is required to develop sound knowledge regarding the key aspects that are deeply rooted in the context of gender issues within the classroom. 


\subsection{Conceptual framework}

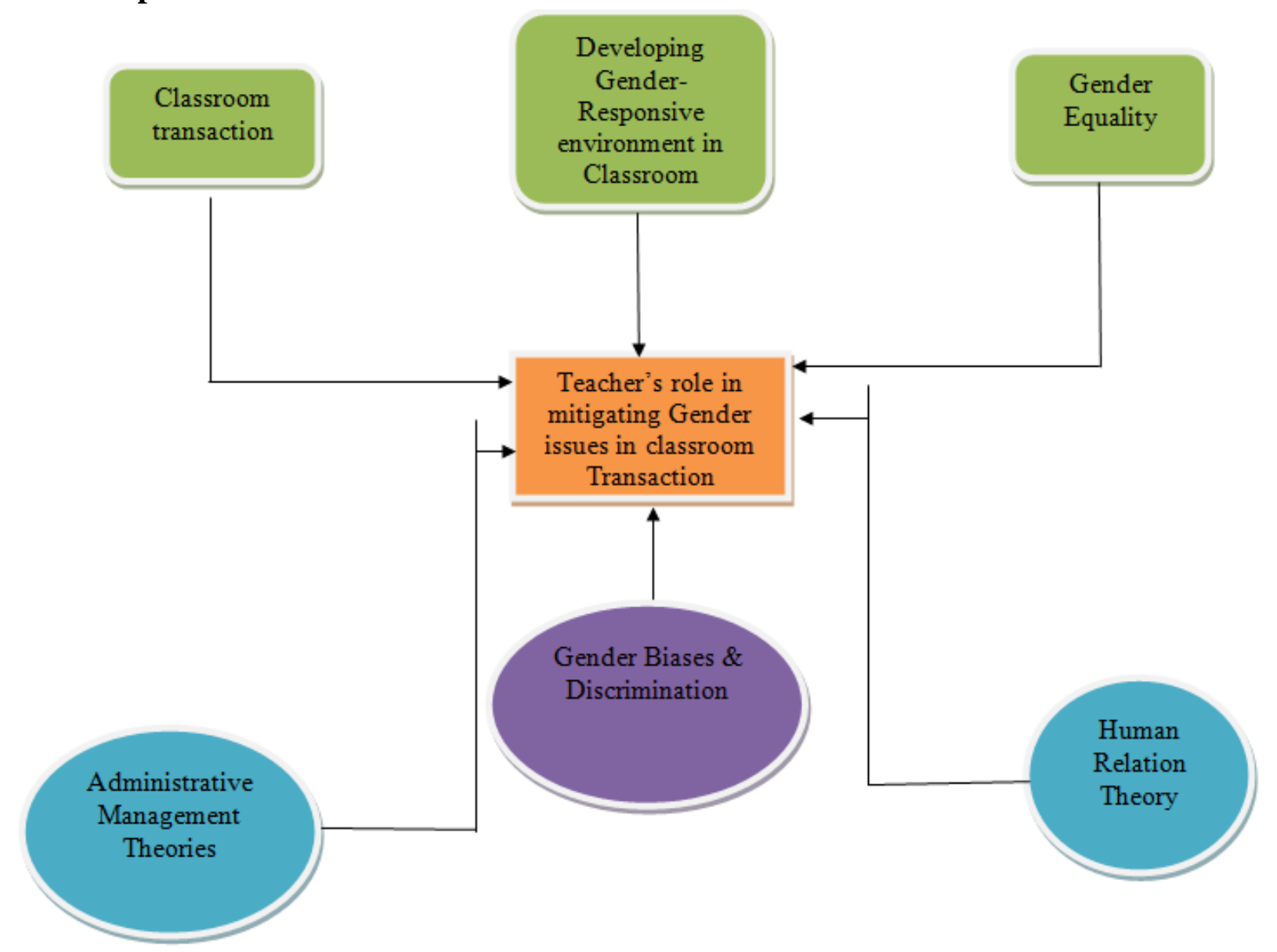

Figure 2.2.1: Conceptual framework

\subsection{Concept Overview}

Classroom transactional practice includes teacher, content, environment, assessment, mode, style etc. For effective classroom practices quality relationships should be built. It takes time to build quality relationships, developing student's ability to make appropriate choices, fostering and maintaining harmonious classroom environments, allowing students to learn from their mistakes and develop strategies for restitution (Kaur, 2016). Within any classroom there is a constant active transactional procedure evolving.

The classroom transaction acts as a unique tool for bringing transformation in learners' intellectual, emotional and social construct. This study proposes a constructive framework that encourages children in a classroom to take part in activities of the classroom through problem solving and asking questions. In this context, a teacher holds great importance in enabling a positive learning environment that rejects the idea of gender biases in a classroom environment.

\subsection{The role of Teacher's in mitigating Gender issues in Classroom Transaction}

In considering the context of the research topic that chiefly relies upon distinguishing the role played by a teacher in eliminating gender biases in a classroom transaction, it has been noted that teachers are the main pillars in the initiation of positive learning and teaching initiatives, 
hence they play a vital role in this venture as well. Through observing several informational sources consisting of significant articles and journals and even experiencing the high sense of gender biases and issues, It cannot be ignored that gender biases are present even in the classroom, to ensure such occurrence does not happen in the periphery of the classroom, only teachers can play the major role(Lee etal. 2019).

\subsection{Advantages of mitigating Gender issues by teachers in Classroom Transaction}

Nurturing gender sensitivity through teacher education, focusing mainly in classroom transactions, bears great significance. The structured school environment and learning environment are highly favourable for imbibing values, especially ones which are related to equality and equity(Sun et al. 2019). The hidden curriculum helps the teachers to inculcate gender sensitisation subtly which gradually seeps into the value system of the learners and builds the character. However, these actions adopted by teachers result in great changes such as developing a sense of prejudice-free mentality towards gender equality, and shapes the mindset of the students to act as responsible men and women in society. This will help in reducing the age-old mentality of gender biases expressed as traditional gender roles that affected the students and improve the ideology of gender inequality in them (Muschkinetal. 2020).

\subsection{Disadvantages of Gender discrimination in Classroom Transaction}

As it has been previously observed that how significant the conceptualization of gender equality is, especially in the periphery of classroom transactions, it can be stated that, there are many disadvantages regarding gender issues in classroom transactions (Gore, 2019). The instances of Gender biases or discrimination are not rare and can harshly impact many aspects associated with the person or the community that is being discriminated based on gender. Gender inequality enables exposure to negative aspects, mainly for students, such as, recent research reflects that there remains a high chance of psychological trauma and mental issues that can be triggered through gender issues, persistent stereotypes, and continuous gender biases can impact the education and physical state of the biased persons (Goudeao and Croizet, 2017).

\subsection{Theoretical perspective}

In this fact, teachers are required to follow "Administrative management theories", by which they can easily reduce the gender issue in classroom transactions. Adapting this theory, from the field of administration and management, the teachers can become effective learning environment managers and can reduce gender issues in the classroom. While considering this theory there are certain factors the teacher should be well aware of (Swain, 2018). Division of work is the first factor, by which teachers can make students more skilled. The work is broken down and assigned to individuals working in groups. Discipline is the second factor that determines the success of attaining an objective. Equity is the next important factor in a learning environment. It ensures equal and fair chances for all. Implementing Unity of direction helps to keep everyone aware of stated objectives of the task and working towards them.(Waylen, 2017). Through these components identified by Henri Fayol and later developed by Luther Gulick, teachers can transform the students to become fair all the time, 
correlating all disciplines and performing with true transfer of learning in appropriate contexts.

\subsection{Literature gap}

Literature gap indicates the inadequacy of information, by which further research is required. However, through the review of related literature, it has been found that Administrative management theories cannot fulfill all requirements to back up the cause of gender sensitisation in a learning environment. Along with this theory, if teachers can follow the essence of Human relation theory, they can improve the classroom performances which in turn bring a change in the intellectual, emotional and social structure of classrooms (Kaur, 2013). The theory based on the inputs of Mayo and Kurt Lewin concludes that democratic groups in which members actively participate in decision making are more productive. It highlights group dynamics.

\subsection{Summary}

In view of the overall outcomes that have been acquired through undergoing an effective critical analysis concerning the role and effectiveness of teachers in mitigating gender issues in classroom transactions, many promising insights have been acquired. The effective evaluation of the concept overview has developed sound knowledge regarding the classroom transaction and the significance of teachers in mitigating the gender issues that emerge in the periphery of the classroom. The evaluation has also developed a vivid understanding on the management techniques based on theories which can bring in a positive learning environment and thus outgrow the biases.

\section{RESEARCH METHODOLOGY}

\subsection{Introduction}

In order to unravel some promising discoveries regarding this research context, secondary qualitative data has been considered for this research. To accumulate relevant data and information for addressing the research methodology, literature analysis was conducted for advancing qualitative data analysis.

\subsection{Research Design and Approach}

The study was conducted following a secondary research method. Secondary analysis serves an important function in educational research (Burstein, 1978). The researcher has found this approach appealing from the perspective of an educational researcher, teacher and as a professional interested in improving own understanding of the profession. Secondary analysis involves re analysis of data for the purpose of answering the original research question or new questions with old data (Glass, 1976). The researcher selected the secondary analysis approach for the present study considering it's feasibility and economy in terms of time and cost for the present research context. 


\subsection{Data collection}

The process of data collection is the most important aspect while drawing a methodological approach thoroughly for any study. Data collection in the present study was done by secondary analysis or desk research which is a unique method of collecting data through relevant and acute sources, in order to seek effective answers regarding the research problems (Crossman, 2020). In this research online sources were extensively used to access books, scholarly journals, websites and blogs. The content available was read extensively to collect relevant information to reach the conclusions mentioned as the findings of the study. The secondary data were gathered through thematic analysis which has also assisted the researcher for this probe in gathering accurate data and information for the research. Best efforts are made to ensure the credibility of the data source by carefully contemplating the domain name given in the address bar of the sites accessed.

\subsection{Data analysis and interpretation}

In relevance with the contextual conceptualization of the research, the aspects of data analysis are highly essential in acquiring relevant and to the point information that can assist in the advancement of the research. Data analysis reflects the method of cleaning, inspecting, modeling, and transforming relevant data and information, with the purpose of attaining appropriate information, reflecting an acute evaluation and interpretation of data. The degree and nature of the analysis used to describe and examine the collected data vary widely by review ( Palmatier, R., 2017). Here the researcher has relied on compiling the related studies on gender issues to get certain preliminary insights into the area which can later lead to indepth studies related to gender issues and mitigation. The analysis of secondary data was considered through developing significant themes through the research objectives and the discussion of these themes has offered ample information to address the research.

\section{ANALYSIS AND INTERPRETATION}

\subsection{Findings and analysis of secondary data}

Theme 1: Education can bridge the gender gap among students during classroom transactions

Based on the analysis, it has been observed that education is the most essential tool for empowering all irrespective of gender. But in the social scenario education for girls needs a special mention in the context of "women empowerment". Even in the 21 st century, in most third world countries educating girl children is considered secondary. Through proper education, boys and girls can be equipped equally to participate in life economically, politically, and socially (Falk and Hermle, 2018). As the concept of gender roles are age old, sometimes even worse than the caste system in India, we can bring a change by starting from class rooms. Education helps to create a democratic society in it's true sense as envisioned by the architects of the Indian constitution. It brings equality of opportunity into practice.

As opined by Shannon et al. (2019), education has the crucial function of changing student attitudes through making a positive psychological impact. Through this, students can easily accept "gender equality", which has been contemplated as the fundamental value of society. 
Thus, in simple words, it can be said that education has been chosen as the "key" for mitigating gender issues during classroom transactions in the educational sector. Gender equality needs to be promoted for women empowerment. Therefore, all levels of education need to be developed for eliminating the gender disparity among the students (unicef.org, 2021).

\section{Theme 2: Teaching strategy is important for addressing gender equality in the classroom}

According to the available information, it can be said that all students need a positive and healthy educational environment. This environment is important for both girls and boys, thus they can get the same opportunities for education. As stated by Salinas and Bagni, (2017), it has been observed that there are many instances in which students cannot get the same opportunities. In that case, teachers need to follow some strategies for supporting "gender equality" in the classroom. A well informed and equipped teacher can create a positive learning environment for all students, in which students feel comfortable to take part equally (unglobalcompact.org, 2021). For this learner centered approaches and strategies can be employed in classroom transactions. The next strategy is to maintain a seating plan for equal participation, by which students' interaction can be improved. In addition to these, group work which encourages collaborative learning is an essential strategy for improving students' activities and right attitudes in the classroom. Project based learning can provide great opportunity to overcome gender differences, if groups are created with boys and girls together doing the same topic of research.

\section{Theme 3: Teachers can play a pivotal role in curbing gender bias in the classroom}

Teachers of educational sectors can play a major role in mitigating gender issues among students during classroom transactions. It has been observed that effective classroom transactions can increase the students' participation (Potvinet al.2018). An active, sustainable engagement of students can bring equality in classroom interactions. However, teachers need to make a deliberate effort to avoid gender bias,like: to use inclusive gender neutral language, avoid stereotyping tasks, ensure expectations, make a motivating classroom environment, and more (unesco.org, 2021). In simple words, by creating a healthy and safe place for these students by providing some role models, teachers can prevent gender bias easily in the classroom.

School is not only a place to acquire knowledge, but a hub where students get a chance to socialise and learn to assume particular roles in society. Therefore teachers should encourage the same positive behaviour from girls and boys, avoiding assigning tasks that involve stereotyped gender roles. Discussions should be initiated in classrooms as a part of curriculum and classroom transactions to understand the depth of the issues and the need to overcome the challenges (UNESCO, 2009). Teachers can play a major role in creating knowledge and understanding in terms and concepts related to gender, more than any others, in students as they are spending a larger amount of time in schools during their developmental stages than at home or any other institutions in society. Teachers can bring attention towards the terms like sex, sexuality, gender, gender parity, gender equity, gender 
equality, empowerment through well-constructed learning approaches which has scientific backup, that ensures unambiguity and misconceptions.

\section{SUGGESTION \& CONCLUSION}

\subsection{Limitations}

Different journals and articles, related to the research topic, have been reviewed for meeting the research aim and objectives properly. Some key and relevant themes have been designed as per research requirements. However, some crucial limitations have been recognized at the time of managing the literature review. Therefore, there is the main loophole, the domains like psychological impact of the students during classroom transactions, which has been pointed out properly (Kaffenberger and Pritchett, 2020) are not examined in-depth. Through studying this research paper, it has been observed that the psychological effect of students for gender inequality, were not clear in the paper. Apart from that, other factors, which cause gender issues like poor medical care, lack of religious freedom, and lack of political representation, are not fathomed in this paper (de Looze et al.2018).

The study mainly focused on the conceptual framework and surveyed studies and articles related to the role of teachers and the adoption of learning strategies in mitigating gender issues. An in-depth review with more statistical analysis can bring out more dimensions and areas of gender where more studies are needed.

\subsection{Conclusion}

Large gender gaps exist in access, learning achievement, and continuation in education in many settings, most often at the expense of girls, although in some regions boys are at disadvantage. Despite progress, more girls than boys still remain out of school (UNESCO Institute of Statistics, 2019). As in many other causes, gender issues can also be prevented through right education. While considering the right education, right learning environment with proper planning in curriculum, pedagogy, methods of teaching and classroom interactions comes into discussion. All these can be achieved through a well-equipped teacher who plays a pivotal role of facilitator in the classroom transactions. But we often overlook the fact that the teacher itself is a product of society in which gender biases exist. This can be overcome by training and transforming teachers through well-structured teacher education programs which focus on the praxis and paradigms of right education.

\section{References}

\section{Books}

- Cole, S. ed., 2018. Gender equality and tourism: Beyond empowerment. United Kingdom: CABI.

- Goetz, A.M., 2018. National women's machinery: State-based institutions to advocate for gender equality (pp. 69-95). Manchester: Manchester University Press.

- Swain, J., 2018. A hybrid approach to thematic analysis in qualitative research: Using a practical example. California: SAGE Publications Ltd.

- Waylen, G. ed., 2017. Gender and informal institutions. United States: Rowman\& Littlefield. 


\section{Journals}

- Adams, N., Pearce, R., Veale, J., Radix, A., Castro, D., Sarkar, A. and Thom, K.C., 2017. Guidance and ethical considerations for undertaking transgender health research and institutional review boards adjudicating this research. Transgender health, 2(1), pp.165175.https://www.liebertpub.com/doi/pdfplus/10.1089/trgh.2017.0012

- Atmowardoyo, H., 2018. Research methods in TEFL studies: Descriptive research, case study, error analysis, and R \& D. Journal of Language Teaching and Research, 9(1), pp.197204.http://academypublication.com/issues2/jltr/vol09/01/25.pdf

- Burstein, L., 1978. Secondary Analysis: An important Resource for Educational Research and Evaluation. Educational Researcher, 7(5):9. SAGE Publications. http://dx.doi.org/10.3102/0013189X007005009.

- Draper, J., Young Thomas, L. and Fenich, G.G., 2018, January. Event management research over the past 12 years: What are the current trends in research methods, data collection, data analysis procedures, and event types?.In Journal of Convention \& Event Tourism (Vol. 19, No. 1, pp. 3-24).Routledge.https://www.researchgate.net/profile/Jason-Draper2/publication/321692456_Event_management_research_over_the_past_12_years_What_are the_current_trends_in_research_methods_data_collection_data_analysis_procedures_and_ev ent types/links/5ad6318a458515c60f55f793/Event-management-research-over-the-past-12years-What-are-the-current-trends-in-research-methods-data-collection-data-analysisprocedures-and-event-types.pdf

- Engeli, I. and Mazur, A., 2018. Taking implementation seriously in assessing success: The politics of gender equality policy. European Journal of Politics and Gender, 1(1-2), pp.111129.

- Etikan, I. and Bala, K., 2017. Sampling and sampling methods.Biometrics \& Biostatistics International Journal, 5(6), p.00149.DOI: 10.15406/bbij.2017.05.00149 https://d1wqtxts 1xzle7.cloudfront.net/56588350/sampling_methods-with-cover-pagev2.pdf?Expires $=1632746876 \&$ Signature $=$ DkFhHe2baajUcULAJ8oFHMyMep8x $\sim$ bdt017ot33YqyFwh0kssvs1YyfR0f4ofrrsrHYjUZ4P8hubzYTZtWFWMZx3UrHFYQV5mUgqglTtDj bQzsJykMp4d5SpJ38YZxNUGwR6glGqnAsIIMECz6Vu2XxePruXxlNECbFjXLf2oiS3sHe UCrZ3HOVm2Oom-

AD zMuHCU7iwojVJUqs5ir4O61wQ8ownO6AqZUUUkdfXJjqo3hujKuMIk1Bhriz EnNG VYA5Uh2fTIA5Fo0RVZaVkUb7 mXzvYki8ssV2hc1RGgsxP98efre2UPeBeL4ubMZbMv WksYQeCNiFnwozJZw_\&Key-Pair-Id=APKAJLOHF5GGSLRBV4ZA

- Falk, A. and Hermle, J., 2018. Relationship of gender differences in preferences to economic development and gender equality. Science, 362(6412).

- Glass, G. V., 1978. Primary, secondary, and meta- analysis of researchEducational Researcher1976510.38, SAGE journals.

- Gore, D.F., 2019. Comparing Academic Performance Data of Students in Single-Gender Classroom: Which Gender Benefits the Most, African-American Males or African-American Females?.

- Goudeau, S. and Croizet, J.C., 2017. Hidden advantages and disadvantages of social class: How classroom settings reproduce social inequality by staging unfair comparison. Psychological science, 28(2), pp.162-170.DOI: $10.1177 / 0956797616676600$ https://www.researchgate.net/profile/Sebastien-Goudeau- 
2/publication/311723483_Hidden_advantages_and_disadvantages_of_social_class_How_clas srooms_reproduce_social_inequality_by_staging_unfair_comparison/links/586d6df808ae8fce 491b5c8a/Hidden-advantages-and-disadvantages-of-social-class-How-classrooms-reproducesocial-inequality-by-staging-unfair-comparison.pdf

- Gupta, G.R., Oomman, N., Grown, C., Conn, K., Hawkes, S., Shawar, Y.R., Shiffman, J., Buse, K., Mehra, R., Bah, C.A. and Heise, L., 2019. Gender equality and gender norms: framing the opportunities for health. The Lancet, 393(10190), pp.2550-2562.

- Kaur, P., 2016. Quality in classroom transaction. International Journal of Multidisciplinary Education and Research. 1(7): 30-32

- Kennedy, A.M., 2017. Macro-social marketing research: philosophy, methodology and methods. Journal of Macromarketing, 37(4), pp.347-355.https://farapaper.com/wpcontent/uploads/2019/11/Fardapaper-Macro-Social-Marketing-Research-Philosophy-

Methodology-and-Methods.pdf

- Kleiber, D., Frangoudes, K., Snyder, H.T., Choudhury, A., Cole, S.M., Soejima, K., Pita, C., Santos, A., McDougall, C., Petrics, H. and Porter, M., 2017.Promoting gender equity and equality through the small-scale fisheries guidelines: experiences from multiple case studies.In The small-scale fisheries guidelines (pp. 737-759).Springer, Cham.

- Lee, J., Rhee, D.E. and Rudolf, R., 2019. Teacher gender, student gender, and primary school achievement: Evidence from ten Francophone African countries. The Journal of Development Studies, 55(4), pp.661-679.

- Moser, A. and Korstjens, I., 2018. Series: Practical guidance to qualitative research. Part 3: Sampling, data collection and analysis. European journal of general practice, 24(1), pp.918.https://www.tandfonline.com/doi/pdf/10.1080/13814788.2017.1375091

- Muschkin, C.G., Ladd, H.F., Dodge, K.A. and Bai, Y., 2020. Gender differences in the impact of North Carolina's early care and education initiatives on student outcomes in elementary school.Educational Policy, 34(2), pp.377-407.

- Palmatier, R. W., Houston, M. B, Hulland, J,. 2017. Review articles: purpose, process and structure. Journal of the Academic Marketing Science, 46:1-5.

- Sun, T., Gaut, A., Tang, S., Huang, Y., ElSherief, M., Zhao, J., Mirza, D., Belding, E., Chang, K.W. and Wang, W.Y., 2019. Mitigating gender bias in natural language processing: Literature review.arXiv preprint arXiv:1906.08976.

- Woiceshyn, J. and Daellenbach, U., 2018. Evaluating inductive vs deductive research in management studies: Implications for authors, editors, and reviewers.Qualitative Research in Organizations and Management: An International Journal.https://www.researchgate.net/profile/Jaana-Woiceshyn2/publication/324596659_Evaluating_Inductive_versus_Deductive_Research_in_Manageme nt_Studies_Implications_for_Authors_Editors_and_Reviewers/links/5b78d9aa92851c1e121f 7477/Evaluating-Inductive-versus-Deductive-Research-in-Management-StudiesImplications-for-Authors-Editors-and-Reviewers.pdf

\section{Online articles}

- Andersson, E., Johansson, M., Lidestav, G. and Lindberg, M., 2018.Constituting gender and gender equality through policy: the political of gender mainstreaming in the Swedish forest industry. Equality, diversity and inclusion: An international journal. Available at https://www.diva-portal.org/smash/record.jsf?pid=diva2:1254711 [Accessed on 17.9.2021] 
- Crossman, Ashley. (2020, August 27). Understanding Secondary Data and How to Use It in Research. Retrieved from https://www.thoughtco.com/secondary-analysis-3026573.

- deLooze, M.E., Huijts, T., Stevens, G.W., Torsheim, T. and Vollebergh, W.A., 2018. The happiest kids on earth.Gender equality and adolescent life satisfaction in Europe and North America. Journal of youth and adolescence,47(5), pp.1073-1085. Available at https://link.springer.com/article/10.1007/s10964-017-0756-7 [Accessed on 17.9.2021]

- Kaffenberger, M. and Pritchett, L., 2020.Aiming higher: Learning profiles and gender equality in 10 low-and middle-income countries. International Journal of Educational Development, 79, p.102272. Available at https://www.sciencedirect.com/science/article/pii/S0738059320304314 [Accessed on 17.9.2021]

- Potvin, D.A., Burdfield-Steel, E., Potvin, J.M. and Heap, S.M., 2018. Diversity begets diversity: A global perspective on gender equality in scientific society leadership. PloS one, 13(5), p.e0197280. Available at https://journals.plos.org/plosone/article?id=10.1371/journal.pone.0197280 [Accessed on 17.9.2021]

- Salinas, P.C. and Bagni, C., 2017. Gender equality from a European perspective: Myth and reality. Neuron, 96(4), pp.721-729. Available at https://www.sciencedirect.com/science/article/pii/S0896627317309315 [Accessed on 17.9.2021]

- Shannon, G., Jansen, M., Williams, K., Cáceres, C., Motta, A., Odhiambo, A., Eleveld, A. and Mannell, J., 2019. Gender equality in science, medicine, and global health: where are we at and why does it matter?. The Lancet,393(10171), pp.560-569.Available at https://www.thelancet.com/journals/lancet/article/PIIS0140-6736(18)33135-

0/fulltext?utm_campaign=tlwomen19\&utm_content=84612626\&utm_medium=social\&utm_ source=twitter\&hss_channel=tw-270132921 [Accessed on 17.9.2021]

Websites

- globalgoals.org (2021), GOAL 5 IN ACTIONAvailable at https://www.globalgoals.org/5gender-equality [Accessed on 17.9.2021]

- unesco.org (2021), Priority Gender EqualityAvailable at https://en.unesco.org/genderequality [Accessed on 17.9.2021]

- unglobalcompact.org (2021), Gender EqualityAvailable at https://www.unglobalcompact.org/what-is-gc/our-work/social/gender-equality [Accessed on 17.9.2021]

- unicef.org (2021), Gender equality Available at https://www.unicef.org/gender-equality [Accessed on 17.9.2021] 